\title{
NEW FUCHSIAS FROM SOUTHERN PERU
}

\author{
IVAN M. JoHnston
}

Fuchsia platypetala, sp. nov.

Frutex 2-3 m. altus; ramulis ascendentibus, juventute pilis curvatis $0.2-0.3 \mathrm{~mm}$. longis saepe brunneis vestitis, maturitate glabrescentibus cortice brunneo obtectis; foliis oppositis vel alternis graciliter 4-15 mm. longeque petiolatis, lamina lanceolata utroque acuta $2.5-7.5 \mathrm{~cm}$. longa quam petiolo saepe 7-plo longiore $1-2.3 \mathrm{~cm}$. lata paullo infra medium latissima penninervia (nervis 6-10-jugis ascendentibus) pilis plus minusve erectis saepe curvatis $0.1-0.3 \mathrm{~mm}$. longis vix abundantibus vestita, subtus pallidiori, supra viridi et inconspicue nervata, margine denticulata; floribus solitariis vel geminatis e axillis superioribus caulinis orientibus et in racemos foliosos laxos cernuos aggregatis; pedicellis gracilibus quam foliis proximis subaequilongis vel longioribus sub anthesi $2-3.5 \mathrm{~cm}$. longis pendulis pilis paucis ornatis; ovario elongato $8-10 \mathrm{~mm}$. longo $1.5-3 \mathrm{~mm}$. crasso aliquantum hispidulo; hypanthio $4.5-5 \mathrm{~mm}$. longo basi bulboso (3.5-4 mm. crasso) deinde constricto ca. $1 \mathrm{~cm}$. supra basim angustiori (2-3 $\mathrm{mm}$. crasso) deinde apicem versus gradatim ampliato, apice ca. $9 \mathrm{~mm}$. diametro, extus sparse hispidulo, intus ad 1 $\mathrm{cm}$. infra apicem piloso deinde glaberrimo; sepalis $1.5-2 \mathrm{~cm}$. longis cuneatis basim versus 3-4 mm. latis apice attenuatis; petalis 14-16 mm. longis obovatis supra medium saltem $1 \mathrm{~cm}$. latis, apice rotundis vel late obtusis; staminibus glaberrimis 8 inaequalibus, majoribus petalis subaequilongis; antheris oblongis ad $3.5 \mathrm{~mm}$. longis; stylo infra medium piloso stigmate colorato leviter quadrifido coronato.

PERU: Chinchero, dept. Apurimac, along lanes in town, semicultivated but reported as wild nearby, shrub 2-3 m. tall, fl. crimson, "Serafina," 2930 m. alt., Nov. 1, 1935, James West 3705 (Type, Univ. Calif.; IsoType, Gray Herb.); Cuzco, cultivated in gardens, shrub 3 m. tall, 3350 m. alt., April 1927, F. L. Herrera 1514 (G).

This is an unusually distinct and handsome species. The large and conspicuous petals are described by the collector as "crimson." The dried material, however, shows the petals as having a large, central, oblong, white or yellowish splotch which extends from the base up to beyond the middle. The remaining parts of the petals are crimson. Similar markings are found near the base of the elongate crimson sepals. 
Fuchsia tincta, sp. nov.

Frutex 1-1.5 m. altus; ramulis fistulosis compressis cum pilis brevibus abundantibus brunnescentibus septatis villosulis; foliis oppositis conspicue (1-2 cm. longe) petiolatis; lamina ovata membranacea $10-15 \mathrm{~cm}$. longa $7-10 \mathrm{~cm}$. lata (infra medium latioribus), apice acuta vel subacuminata, basi obtusa, margine evidenter denticulata, subtus (nervis conspicuis 10-16-jugis excepta) purpureo-tincta inconspicue villosula, supra viridi opaca minutissime vesiculifera abundanter vel inconspicue villosula; floribus in corymbulis terminalibus laxis paucifloris foliaceobracteatis; pedicellis ascendentibus gracillimis $1.5-2 \mathrm{~cm}$. longis villosulis quam bracteis foliaceis longiorioribus vel brevioribus; ovario $4-5 \mathrm{~mm}$. longo dense villosulo; hypanthio 20-22 mm. longo, basi bulboso 1-1.5 $\mathrm{mm}$. diametro deinde constricto, $5 \mathrm{~mm}$. supra basim angustiore (ca. 0.8 $\mathrm{mm}$. crasso) deinde apicem versus gradatim ampliato, apice 3-4 $\mathrm{mm}$. crasso, extus subglabro, intus in quarta parte superiore glabro ceteris conspicue retrorseque villosis; sepalis ca. $9 \mathrm{~mm}$. longis triangularibus basi ca. $3.8 \mathrm{~mm}$. latis apice acutis; petalis $6-7 \mathrm{~mm}$. longis oblongo-ovatis medium versus $4 \mathrm{~mm}$. latis, apice obtusis mucronatis, quam sepalis evidenter brevioribus; staminibus evidenter inaequalibus, longioribus petalis aequilongis vel brevioribus; stylo infra medium evidenter villosulo ceterum glabro; stigmato late 4-lobulato; fructu submaturo ellipsoideo $7 \mathrm{~mm}$. longo $4.5 \mathrm{~mm}$. crasso sulcato.

Peru: Rio Tambomayo, prov. Paucartambo, dept. Cuzco, undershrub 1-1.5 m. tall, in forest of upper montaña, 1800-2200 m. alt., calyx deep crimson, corolla crimson-scarlet, July 25, 1936, James West 7092 (TYpe, Univ. Calif.; Isotype, Gray Herb.).

This species is probably most closely related to $F$. macrophylla Johnston and to $F$. asperifolia Krause, of central Peru, but may be readily separated from them by its broader, more herbaceous denticulate leaves which are purplish beneath.

\section{Fuchsia austromontana, sp. nov.}

Frutex 3-4 m. altus, laxe ramosus; foliis saepe ternatis; lamina 2.2-5 $\mathrm{cm}$. longa $0.8-2.3 \mathrm{~cm}$. lata ovato-lanceolata vel lanceolata vel non raro plus minusve oblanceolata in venis 4-7-jugis plus minusve villosula ceterum glabrescente paullo infra medium vel supra medium latiore deinde apicem versus in acumen gradatim attenuata, basi acuta, margine denticulata, subtus pallida supra viridi; petiolo 2-4 $\mathrm{mm}$. longo dense villosulo; pedicellis in axillis folii saepe solitariis quam foliis brevioribus 1-2 cm. longis glabratis; ovario glabro vel sparse villosulo cylindrico 6-8 mm. longo 2-2.5 mm. crasso; hypanthio $2.5-4 \mathrm{~cm}$. longo, extus sparse 
villoso, intus in tertia parte inferiore villoso ceterum glabro, basi bulboso 3-5 $\mathrm{mm}$. crasso, $1 \mathrm{~cm}$. supra basim angustiore $(2.5-3 \mathrm{~mm}$. crasso) deinde apicem versus gradatim ampliato; sepalis lanceolatis $15-17 \mathrm{~mm}$. longis, basi ca. $4 \mathrm{~mm}$. latis; petalis late obovatis $14 \mathrm{~mm}$. longis $11 \mathrm{~mm}$. latis in sicco purpureis apice rotundis quam sepalis $2-4 \mathrm{~mm}$. brevioribus; staminibus inaequalibus, longioribus quam sepalis paullo brevioribus; stylo usque ad basim glabro; fructu ignoto.

Peru (dept. Cuzco, prov. Paucartambo): between Pillahuata and Acanacu, woods of "ceja de la montaña" formation, among shrubs, 2000 m. alt., shrub 3-4 m. tall, flowers brilliant scarlet, large, corolla somewhat lighter shade than calyx, July 26, 1936, James West 7083 (TYPE, Univ. Calif.; Isotype, Gray Herb.); thickets in valley of paramo above Pillahuata, Cerro de Cusilluyoc, 3000-3300 m., shrub with petals "scarletred," May 1925, Pennell 14110 (G).

In shape, size, and texture the sepals and hypanthium of the present species much suggest those of $F$. denticulata R. \& P. The petals, however, are very broad and rounded, rather than elongate and acute as in $F$. denticulata. The petals of both species become purplish when dry. The relations of $F$. austromontana are probably closest, however, with $F$. leptopoda Krause. It differs from that species in its smaller leaves, broad petals, and coarser less slender hypanthium.

\section{Fuchsia chloroloba, sp. nov.}

Frutex usque ad $1 \mathrm{~m}$. altus; radice tuberifera; ramis subsimplicibus elongatis; foliis alternatis conspicue ( $1-4 \mathrm{~cm}$. longe) graciliterque petiolatis superioribus gradatim reductis; lamina carnosula glabrescente lanceolata $5-12 \mathrm{~cm}$. longa $2-3(-4.2) \mathrm{cm}$. lata, basi rotunda vel acuta, medium versus vel infra medium latiore deinde in acumen asymmetricum gradatim attenuata, margine denticulata vel integra, subtus pallidiore, nervis saepe 6-8-jugis; floribus in ramis virgatis terminalibus et aggregatis vel in axillis superioribus folii solitariis; pedicellis $2-5 \mathrm{~cm}$. longis; ovario 8-12 mm. longo glabro cylindrico 1-2 mm. crasso; hypanthio 4.5$8.5 \mathrm{~cm}$. longo, basi $2.5-5 \mathrm{~mm}$. crasso deinde gradatim contracto (1-1.2 $\mathrm{cm}$. supra basim hypanthii angustissimo et 1-2 mm. crasso) deinde in tubum subcylindricum $(7-12 \mathrm{~mm}$. crassum) plus minusve abrupteque expanso, extus glaberrimo, intus usque ad $1 \mathrm{~cm}$. supra basim villoso ceteris glaberrimo; sepalis triangularibus $13-18 \mathrm{~mm}$. longis acutis, basi 5-7 mm. latis; petalis nullis; staminibus inaequalibus, longioribus 4 quam sepalis brevioribus et quam brevioribus ca. $5 \mathrm{~mm}$. longioribus; fructu 2-2.3 cm. longo glaberrimo.

Perú (dept. Cuzco, prov. Paucartambo): eastern slopes of Andes 
above Cosñipata, $3100 \mathrm{~m}$. alt., flower rose-colored with greenish lobes, April 1914, Weberbauer 6935 (G); Pillahuata, Cerro de Cusilluyoc, 2200-2400 m., shrub on open rock cliff above river, calyx-tube "scarlet," lobes "courge green," May 1925, Pennell 13973 (туре, Gray Herb.); Rio Tambomayo, between Pillahuata Bridge and head of Tambomayo grade, 1600-2300 m., forest of upper montaña zone, chiefly epiphytic but occasionally terrestrial in humus, almost stemless to a bush $1 \mathrm{~m}$. tall, roots with long clusters of tubers, nearly leafless at this season, flowers pendant with bright scarlet tube and parrot-green lobes, July 1936, James West 7094 (G).

An apetalous species related to $F$. salicifolia Hemsl. and to the probably synonymous $F$. juntasensis Kuntze. The present species is a larger plant throughout and has green sepals.

Arnold Arboretum,

HARVARD UNIVERSITY. 


\section{$2 \mathrm{BHL}$ Biodiversity Heritage Library}

Johnston, Ivan M. 1939. "New Fuchsias from Southern Peru." Journal of the Arnold Arboretum 20(2), 241-244. https://doi.org/10.5962/p.185413.

View This Item Online: https://www.biodiversitylibrary.org/item/33596

DOI: https://doi.org/10.5962/p.185413

Permalink: https://www.biodiversitylibrary.org/partpdf/185413

\section{Holding Institution}

Missouri Botanical Garden, Peter H. Raven Library

\section{Sponsored by}

Missouri Botanical Garden

\section{Copyright \& Reuse}

Copyright Status: In copyright. Digitized with the permission of the rights holder.

Rights Holder: Arnold Arboretum of Harvard University

License: http://creativecommons.org/licenses/by-nc-sa/3.0/

Rights: https://biodiversitylibrary.org/permissions

This document was created from content at the Biodiversity Heritage Library, the world's largest open access digital library for biodiversity literature and archives. Visit BHL at https://www.biodiversitylibrary.org. 